are attractively produced, sometimes strikingly beautiful, and, so far as can be judged, true to life.

There is no doubt that this work is a valuable contribution to marine zoology and in particular to our knowledge of the Opisthobranchiata of Far Eastern seas ; but let us hope that the Emperor and his team of investigators will see fit to follow it up with further publications dealing with some other aspects of the biology of this interesting group of the Mollusca. With such admirable facilities for study in what must be the finest of collecting grounds, it is not too much to expect that observations on general biology, spawning habits and larval and post-larval development, to mention only a few of the topics on which detailed information is so sadly lacking, will be undertaken.

The book is expensive in British money; but it is well printed and in all respects most attractively produced. It is stoutly bound in pale green with gold lettering -in English on the cover and Japanese on the spine. To the British reader, who can scarcely be expected to boast familiarity with all the localities mentioned, the inclusion of a large-scale map of Sagami Bay and neighbourhood would have been an asset.

J. E. FORREST

1 Bergh, R., Verh, k.k. zool.-bot. Gesell., Wien, 30, 31 (1880-81)

- Eliot, C., J. Coll. Sci. Imp. Univ. Tókyô, 35, Art. 1 (1913).

\section{TEXT-BOOK OF LIGHT FOR DEGREE STUDENTS}

Light

(Student's Physics Series, Vol. 1.) By Prof. R. W. Ditchburn. Pp. xxii+680. (London: Blackie and Son, Ltd., 1952.) 45s.

7 HIS book is a most welcome addition to the series which contains, for example, J. K. Roberts's "Heat and Thermodynamics". Despite the multiplicity of books on the subject of light, there are few which are suitable for honours students, and still fewer which approach the degree of completeness and attention to detail shown by this volume. Prof. R. W. Ditchburn is to be congratulated on the production of a work which is a testimony both to his extensive knowledge of the subject and to his powers as a teacher.

The book covers all that is required in physical optics for a degree course, starting from Intermediate level ; it does not include geometrical optics, as the title might imply. Problems, on which the student can test his powers, are interspersed throughout the book, and often brief guides to the methods of solution are given.

Having made clear my unqualified opinion of the book as a whole, I should like to direct attention to two aspects in which I feel that the author does not live up to the high standard which he has set for himself. First, he claims, in the preface, that the wave theory has been described in such a way that the quantum theory appears as a natural development. One looks forward to some interesting new approach to the teaching of this rather awkward episode in the history of science, but it is not there ; one meets the usual presentation of the quantum theory as a device for explaining, for example, odd effects such as photoelectricity.

Secondly, it is possible that more could be made of Abbe's theory of image formation. I agree that the treatment is at least as full as in any other text-book of light; but, in a book in which so much attention is paid to practical details, it is a pity that the author has not taken the opportunity to reproduce some practical illustrations, which would make the theory so much more real to the student. The concept of resolving power is of such importance in physics that it is unsatisfactory merely to refer students to the original work, which is often not readily accessible to them.

The difficulty is aggravated by the fact that the only practical illustration related to resolving power (Fig. $l$, Plate III) is given a misleading legend ; it is actually the Fraunhofer diffraction pattern of a single circular aperture obtained from two point sources near the limit of resolution, but it is described as the "pattern due to two circular apertures which are just resolved".

These are the only aspects of the book which I feel to be unsatisfactory. There are some very minor errors, such as the omission of two minima in Fig. 6.3, and the mention of "the molecule" of mica ; but, on the whole, the reading of the book can engender nothing but admiration that one man can cover so adequately the different aspects of physical optics.

H. LIPSON

\section{LEAF-MINING INSECTS}

\section{Biology of the Leaf Miners}

By Prof. E. Martin Hering. Pp. iv + 420. ('s-Gravenhage: Dr. W. Junk, 1951.) 36 guilders.

DRIMARILY, this book is an investigation into the feeding patterns of leaf-mining insects and is the result of years of research by Prof. E. M. Hering on the leaf-mining habit. It is an attempt, based on the nature of the damage inflicted on the plant, which is in itself dependent upon the specific behaviour of the individual species, to identify, often down to species level, a diverse collection of insects.

The first chapter includes the definition and classification of the miners ; each type of $\min \theta$, which is well illustrated, is given a specific name depending upon its shape and form and the part of the plant where it is to be found. The following chapter deals with fundamental morphological characters which separate the four orders of insects-namely, the Lepidoptera, Coleoptera, Diptera and Hymenopterato which the leaf-mining habit is restricted. It also discusses the modifications in structure of the larvæ induced by the mining habit and emphasizes the disparities existing between mines caused by members of the different orders.

The author then considers the general life-history of mining insects, with much space devoted to the pupal stage, which tends to show greater variance between species, particularly concerning the selection of pupation sites. There is a tendency for leaf-mining insects to complete their life-history in a shorter time than that required by other phytophagous insects. Reasons for this, such as the consumption of highly nutritious food material and the uniformity of the micro-habitat, are dealt with in a separate chapter.

The extent of Prof. Hering's studies is indicated by the next chapter on disposal of frass, where he utilizes the types of frass deposition as a means of identification. In addition, the problem associated with the disposal of frass to prevent contamination of the mines is discussed. 